\title{
REDEFINIÇÃO DA CENTRALIDADE URBANA EM CIDADES MÉDIAS
}

\author{
Redefinition of the urban centrality in medium-sized cities
}

\author{
Gilberto Alves de Oliveira Júnior \\ Mestrando do Programa de Pós-Graduação em Geografia \\ Universidade de Brasília - UnB
}

Artigo recebido para publicação em 10/11/2007 e aceito para publicação em 28/02/2008

RESUMO: O texto ora apresentado realiza um esforço reflexivo cujo objetivo principal é analisar os processos de descentralização e recentralização em cidades médias que, conjugados, resultam em novas centralidades e na redefinição da centralidade nessas cidades. As novas centralidades expressam a saturação dos centros tradicionais para as necessidades impelidas pelas novas formas contemporâneas de reprodução e acumulação do capital, além da imposição de (novos) tempos hegemônicos. Assim, são criados e inseridos novos artefatos que favorecem e aperfeiçoam a reprodução capitalista do espaço: o espaço como produto social constrangido pela acumulação do capital. Dessa forma, depreende-se que as alterações na dinâmica econômica determinam que a cidade possua novas centralidades porque as tradicionais não são mais funcionais à reprodução e acumulação do capital, bem como ao acolhimento de novos capitais que se descentralizam para os espaços que economicamente apresentam-se como mais propícios e rentáveis.

Palavras-chave: Urbanização. Centralidade urbana. Cidades médias.

ABSTRACT: The presented article realizes one effort reflective whose main objective is to analyze the processes of decentralization and recentralization in medium-sized cities that, conjugated, result in new centralities and the redefinition of the urban centrality in these cities. The new centralities express the saturation of the traditional urban centers for the necessities impelled for the new forms contemporaries of reproduction and accumulation of the capital, beyond the imposition of (new) hegemonic times. Thus, new space forms are created and inserted in the urban space that favors the capitalist reproduction of the space: the space as social product urged by the accumulation of the capital. Of this form, it is inferred that the alterations in the economic dynamics determine that the city possess new centralities because the traditional urban centers are not more functional to the reproduction and accumulation of the capital, as well as the shelter of new capitals that if they space decentralize for the spaces that economically are presented as more propitious and income-producing.

Keywords: Urbanization. Urban centrality. Medium-sized cities.

\section{INTRODUÇÃO}

O presente artigo é resultado de um esforço reflexivo acerca das novas formas contemporâneas de reprodução do capital e suas implicações quanto à redefinição dos papéis das cidades médias. Com tal

Sociedade \& Natureza, Uberlândia, 20 (1): 205-220, jun. 2008 
intento, o debate encontra-se centrado essencialmente nas modificações decorrentes da dinâmica econômica, haja vista que no momento atual estas cidades assumem novas funções articuladas ao suprimento das presentes necessidades de reprodução e acumulação do capital e à ampliação do mundo da mercadoria.

Nessa direção, e com o intuito de estabelecer um diálogo com a teoria espacial, objetiva-se construir um breve debate a partir da emergência de novas centralidades em cidades médias que realize uma leitura dos processos e fenômenos que permeiam a criação e consolidação dessas centralidades com a articulação de ordens e racionalidades globais e locais que cada vez mais apresentam-se visceralmente imbricados, revelando a imposição de técnicas e racionalidades hegemônicas em escala mundial.

Isso implica em considerar as (novas) formas contemporâneas com que as atividades econômicas dos diversos ramos comerciais e de serviços vêm se organizando espacialmente como parte de um processo de concentração econômica nas metrópoles que se acompanha de desconcentração espacial, bem como as formas de competitividade que se desenvolvem entre as cidades de porte médio para se apresentarem mais rentáveis e propícias para receberem os investimentos que se desconcentram espacialmente.

Desta forma, apresenta-se como de fundamental importância o estudo dessas transformações - que impelem uma nova orientação tanto para o crescimento urbano quanto para a formulação e aplicação de políticas espaciais urbanas — para a compreensão dos novos processos geradores de fluxos de capital, mercadorias, pessoas, dentre outros, que estão assentados em novas formas de comércio e dos serviços urbanos modernos, ou em outras palavras, em novas formas de reprodução e acumulação do capital.

$\mathrm{O}$ artigo encontra-se dividido em três partes, além da introdução. No primeiro momento, realizase um debate acerca da conceituação de cidades médias; posteriormente, a partir do conceito de estruturação urbana apresenta-se uma discussão teórica acerca das implicações da redefinição da centralidade na dinâmica intra-urbana; por fim, os dois primeiros debates se conjugam na última parte, na qual se desenvolvem algumas idéias sobre a redefinição da centralidade em cidades médias.

\section{Notas acerca do debate sobre cidades médias}

O processo de urbanização que se acentuou consideravelmente no decorrer do século XX trouxe consigo rupturas e permanências que incidem nos processos de produção e estruturação do espaço urbano. Essas são notáveis quando se considera tanto a escala intraurbana quanto a escala interurbana, em âmbito regional, nacional ou mundial.

Essa urbanização acentuada possui como uma das suas características mais expressivas uma elevada concentração de população em poucas cidades em diferentes países do mundo. A concentração de população está aliada também a uma concentração econômica, cultural, de infra-estrutura, informação, poder de articulação, assim como dos problemas e conflitos gerados pelo capital. Tais problemas e conflitos são constituídos e se expressam em diferentes ordens complexamente inter-relacionadas entre si: econômica, social, política, ambiental, dentre outras, que se traduzem em questões relevantes como habitação, saneamento, segurança, acessibilidade, lazer, segregação.

Nesse sentido, é notório que um número considerável destas análises se concentra na metropolização devido à própria escala privilegiada de análise dos processos de reprodução e urbanização da sociedade e acumulação do capital. Estudos recentes têm observado a relevância da concentração de população em grandes áreas urbanas que, dentre outros problemas sociais, espaciais e ambientais, tece uma rede urbana desequilibrada.

Um dos enfoques recentes acerca das cidades médias se concentra exatamente na gestão e planejamento territorial a partir de redes urbanas mais equilibradas. Essa perspectiva coloca as cidades médias, e seu papel de intermediação, em evidência

Sociedade \& Natureza, Uberlândia, 20 (1): 205-220, jun. 2008 
nos mais diversos países do mundo, mas especialmente nos países considerados subdesenvolvidos ou em desenvolvimento.

Isso porque, nos países subdesenvolvidos encontram-se atualmente 15 das 20 cidades com população superior a 10 milhões de habitantes no mundo residindo em áreas consideradas urbanas (UNITED NATIONS, 2006), fato que expressa a macrocefalia e o desequilíbrio da rede urbana nesses países.

O crescente número de estudos sobre cidades médias nas últimas décadas, que denotam uma específica preocupação com a sua (in)definição, aponta para a fragilidade teórica que historicamente embeveceu a construção do seu conceito, ainda impreciso, como também para uma mudança de papéis e portanto da própria relevância das cidades médias na rede urbana e para a incidência, nesses espaços, de fenômenos sócioespaciais que antes estavam restritos às metrópoles.

Alguns estudos recentes vêm demonstrando que estes fenômenos têm servido para modificar, inclusive, a dinâmica do processo de estruturação destas cidades. Entretanto, estes fenômenos não podem ser considerados - por uma simplória analogia desmedida - idênticos aos das grandes cidades, o que pressupõe a necessidade de um instrumental analítico-conceitual específico para as cidades médias. Neste sentido, este instrumental deve estar comprometido em procurar compreender esta categoria de cidades na totalidade do movimento contemporâneo de urbanização da sociedade e acumulação do capital.

Nessa direção, nota-se que os estudos sobre cidades médias devem não apenas constar de elementos estritamente empíricos devido essencialmente à sua indefinição conceitual, o que termina por implicar que uma das relevâncias destes estudos, no plano acadêmico, seja a de contribuir para o desenvolvimento da sua definição, ou de não se furtar em discutir seu conceito, que se encontra hoje sob expressivo e candente debate.
Tradicionalmente as cidades médias têm sido essencialmente definidas de acordo com o seu porte demográfico, sendo que estes números inevitavelmente sofrem modificações ao longo do tempo. Evidentemente que de acordo com uma determinada quantidade de habitantes se torna mais provável que as cidades venham a desempenhar determinadas funções características de cidades médias, e assim exerçam uma polarização sobre a sua hinterlândia. De qualquer forma, é inegável que a prescrição e anuência de um aporte estritamente quantitativo, quanto a demografia para defini-las, é insatisfatório, sem consistência, bem como também não é determinante, embora possua sua relevância, devendo a demografia ser congregada a outras variáveis e fatores, tanto quantitativos quanto qualitativos.

Essa "tradição" quantitativa coloca em evidência que é extensa a diversidade entre as cidades médias, e essa diversidade se apresenta como característica fundamental dessa categoria de cidades. Isso termina por conduzir à constatação da utilização de critérios diferentes para a sua definição, que tendem a variar de acordo com as escolhas de cada pesquisador quanto ao que este considera ou estabelece como relevante ou irrelevante na construção da sua definição, ou simplesmente em determinada classificação ou levantamento de cidades médias para fins diversos.

Decerto, a escolha dessas variáveis leva sobre si um peso político, ideológico, dentre outros, e nesta direção iluminam o processo de urbanização e a realidade concreta das cidades médias diferencialmente, velando ou desvelando problemas e conflitos, supervalorizando ou desprezando soluções e estratégias.

Dessa forma, as diferentes variáveis que embasam as definições de cidades médias e eclodem em perspectivas divergentes, em certo sentido, expressam uma consistente dificuldade de congregar e sintetizar a evidente amplitude da heterogeneidade que compreende a realidade das cidades médias. A tal fato se agrega que as cidades médias se incorporam 
de mais complexidade de síntese conceitual quanto menor a escala de análise, nas quais evidencia-se ainda mais as disparidades existentes entre as cidades consideradas médias. Em outras palavras, nota-se que é crescente a dificuldade na definição de cidades médias quando parte-se de um nível de escala local ou microrregional para a mundial, passando por todas as escalas que se possam considerar entre essas duas extremidades.

As nuances e imbricações espaço-temporais (de)compostas e recompostas pela desigualdade e diferenciações inerentes no/do processo de (re)produção social do espaço condicionam, assim como também (re)arranjam os papéis e a relevância das cidades médias na rede urbana em diferentes escalas, nas quais se articulam e se interpenetram questões políticas, econômicas, culturais, dentre outras.

Embora considerando-se que as diferentes temporalidades se conjugam no mesmo tempo presente, no mesmo espaço, essas se articulam desigualmente, resultando em espaços diferenciados e fragmentados, implícitos ao movimento de reprodução social. Esse movimento congrega conteúdos novos em embate com velhos, modificando e sendo modificados pelo perpétuo rearranjo (econômico-social) no/do espaço, o que significa que variáveis estatísticas rígidas encontram cidades médias diversas numa escala temporal, quando comparadas as décadas de 1950, 1970 e a atual, por exemplo. Disso se depreende que uma das contextualizações para a definição de cidades médias é a temporal.

Estudos recentes, como os de Bellet Sanfelíu e Llop Torné (2004a) e Castello Branco (2006), dentre outros, apontam para outros aspectos qualitativos e quantitativos que subsidiam com maior propriedade uma definição e classificação ou tipologia de cidades médias.

Há ainda o embate entre a utilização do termo ou adjetivo de cidade média ou cidade intermédia. Segundo Bellet Sanfelíu e Llop Torné (2004a) o uso do adjetivo intermédia começou a ser efetivado com considerável aceitação no meio acadêmico no decorrer da década de 1980. Os autores consideram que esse adjetivo dilata o significado da denominação que ele substitui, na medida em que cidade média tem relação direta com critérios quantitativos excessivamente rígidos e estáticos, que serviram, e ainda servem, para tornar oculta a função principal desempenhada por esse tipo de cidades: a da intermediação entre os espaços locais e os espaços regionais, nacionais e, em alguns casos, inclusive globais.

Outra questão relevante na definição de cidades médias/intermédias é que por se encontrarem entre dois extremos (pequenos núcleos urbanos e grandes aglomerações urbanas) são definidas como uma espécie de "conceituação negativa": cidades médias/intermédias são aquelas que nem são grandes nem são pequenas, o que mais uma vez traz ao centro do debate o problema quantitativo, que, como dito, tem sua relevância, embora deva ser contextualizado. Uma cidade de 200.000 habitantes, a título de exemplo, está contextualizada diferencialmente na realidade brasileira, estadunidense, portuguesa, francesa, chinesa etc. Até mesmo na realidade brasileira, decerto que uma classificação que apresente um nível profundo de rigidez é com certeza problemática pelo vasto contraste existente entre as regiões do país.

Assim, ao defender a denominação de cidade intermédia, Bellet Sanfelíu e Llop Torné (2004a) expressam a opinião de que o adjetivo "intermédia" introduz três novas dimensões que anteriormente encontravam-se "veladas" pelo adjetivo "média": (1) acrescenta a idéia de que a importância da cidade não depende tanto do seu tamanho demográfico como do modo como se articula com o restante dos elementos do sistema; (2) realça e introduz aspectos mais dinâmicos e estratégicos da cidade na rede urbana; (3) supõe a substituição do sentido estático e hierarquizado por uma nova idéia mais aberta, dinâmica e interativa (apud DEMMATEIS, 1991).

Isso significa que essa divisão que se propõe ao debate entre a utilização do termo cidade média

Sociedade \& Natureza, Uberlândia, 20 (1): 205-220, jun. 2008 
ou cidade intermédia não é apenas pautado num ponto de vista meramente semântico, mas sim compreende a existência de duas vertentes com determinadas distinções no que tange ao processo científico de permear o fenômeno de modo a apreender sua essência e revelar seu papel no processo de urbanização contemporâneo. No contexto desses debates, incontestavelmente, a construção conceitual de cidades médias/intermédias adquire novos contornos e horizontes.

Para Bellet Santelíu e Llop Torné (2004a), as cidades intermédias se convertem em centro de serviços e equipamentos (mais ou menos básicos) de que se servem tanto os habitantes do mesmo núcleo urbano como aqueles que residem em sua área de influência, sendo centros de serviços que interagem com amplas áreas territoriais, sendo estas mais ou menos imediatas. Para isso, desenvolvem funções de distribuição e intermediação, sendo dotadas de uma série de infra-estruturas coletivas, com destaque para a comunicação e o transporte.

A este conjunto de cidades também é associada uma melhor qualidade de vida, que, entretanto, se traduz muitas vezes numa forma de marketing e promoção urbana e de determinados setores da economia, além de pessoal quando diretamente associada aos gestores e administradores públicos. Expressa-se, ainda, na valorização de publicações de rankings de qualidade de vida das cidades, premiações pela qualidade dos serviços coletivos, dentre outros.

Castello Branco (2006), ao realizar uma análise das cidades médias no Brasil, aponta para o crescimento da importância que estas cidades vêm adquirindo nas últimas décadas no país, fato que se expressa tanto no crescimento do número de cidades médias quanto no incremento populacional expresso nestas cidades.

Com objetivo de contribuir com a definição de cidades médias, Castello Branco (2006) conclui que embora o tamanho demográfico deva ser considerado no processo de investigação, deve-se ressaltar que tanto a localização destas cidades quanto o sistema de transportes em que está inserida tem enorme peso no tamanho da população. Ressalta ainda a importância do tamanho econômico e do grau de urbanização, além da qualidade de vida urbana, mas atribui como essência das cidades médias a centralidade.

A autora reforça que, neste sentido, é preciso considerar que a não inclusão das cidades que se encontram inseridas em regiões metropolitanas ou polarizadas por capitais de estados ou províncias na classificação de cidades médias se deve ao fato de que estas cidades certamente não possuiriam as condições necessárias para polarizar sua hinterlândia e exercer as funções de centralidade e intermediação com outras escalas, tomadas como ponto de partida para a definição de cidades médias.

De acordo com as análises de Sposito (2006), depreende-se que a centralidade compreende um princípio de proximidade que resulta na estruturação das cidades médias como área ou região. Embora, no momento atual, a proximidade, que condiciona a estruturação da cidade em área ou região - e expressam a centralidade da cidade —, não possa ser o único ou principal aspecto da definição desta categoria de cidades, que se encontram atualmente inseridas nas possibilidades oriundas da conectividade. Isso implica na inserção das cidades médias em redes de articulações de diferentes escalas espaciais que não necessariamente necessitem de continuidades territoriais, o que significa que paralelamente ao seu papel regional, as cidades médias exercem novos papéis. Desta forma, cumpre compreender como e porque no momento atual os papéis das cidades médias se modificam e se redefinem.

Assim, a partir do final da década de 1970, com a crise de acumulação do capital implicando num processo de reestruturação produtiva, as cidades médias revestem-se de novos atributos que cada vez mais se apresentam como não mensuráveis sob os critérios quantitativos rígidos que historicamente consubstanciam a definição desta categoria de cidades. 
E, neste sentido, as redefinições atuais dos papéis das cidades médias se embebem de ordens e racionalidades globais e locais que se entrecruzam e se interpenetram visceralmente. Esse movimento atribui então novos papéis aos territórios nãometropolitanos frente ao processo de mundialização do capital, dentre os quais se destacam as cidades médias por apresentarem os requisitos necessários às novas necessidades de alocação do capital.

Nests direção, e em função desses novos momentos e processos inseridos na dinâmica da produção social do espaço, se criam novas centralidades na escala intra-urbana. Essas expressam muitas vezes a saturação dos centros tradicionais para as necessidades impelidas pelas novas formas contemporâneas de reprodução e acumulação do capital, além da imposição de (novos) tempos hegemônicos.

Além disso, as novas centralidades expressam também o intuito de fragmentar a cidade em lugares cada vez mais definidos pelas estratégias dos agentes imobiliários - estratégias estas que se definem pela mediação do mercado capitalista. Assim, são criados e inseridos novos artefatos que favorecem e aperfeiçoam a reprodução capitalista do espaço: o espaço como produto social constrangido pela acumulação do capital como sistema metabólico social.

Essas centralidades também sugerem um processo de (re)valorização do espaço urbano, na medida em que a atração exercida por estas áreas implica em alterações no preço e acesso à terra urbana, principalmente no entorno imediato a estas novas centralidades.

Sob essa perspectiva é que nas cidades médias, a partir deste novo momento do processo de urbanização, nota-se dentre as inúmeras características que se destacam a partir da década de 1970, que é recorrente em diferentes pesquisas recentes a relevância do desenvolvimento da tendência à insurgência de atividades e equipamentos comerciais e de serviços territorialmente descentralizados, ou seja, que se localizam territorialmente em áreas exteriores ao centro principal das cidades.

Estudos recentes, como os de Sposito (1991, 1998, 2001), Silva (2001) e Soares (2003) vêm demonstrando que estes equipamentos que insurgem territorialmente descentralizados são capazes de gerar e manter fluxos que, ao se estabelecerem e se intensificarem, consolidam a criação de uma nova expressão de centralidade, o que redefine a própria noção de centralidade no espaço urbano.

\section{Centro, centralidade e (re)estruturação do espaço urbano}

A cidade consolida-se como centro de comando para a economia capitalista. Nela, o capital concentra os seus meios de produção, circulação e realização, subjugando o trabalho do homem e, por conseguinte, as relações sociais às suas necessidades de reprodução. Neste sentido, a cidade se produz pautada em espaços hierarquizados, segmentados, fragmentados e fraturados; o capital limita e diferencia a apropriação e uso do solo urbano, segrega classes e camadas sociais.

Por tudo isso, a cidade coaduna as melhores condições para o processo de reprodução do capital, e isto implica em conflitos que se refletem na própria reprodução da vida, no cotidiano da sociedade e das suas classes. Pois "o processo de produção da cidade [é] indissociável do processo de reprodução da sociedade - neste contexto a reprodução continuada da cidade se realiza enquanto aspecto fundamental da reprodução ininterrupta da vida" (CARLOS, 2004, p. 19).

A cidade é, portanto, expressão da simultaneidade das contradições do capitalismo nos conflitos engendrados sob o invólucro da sua apropriação privada, e neste sentido é reproduzida, (re)valorizando (diferencialmente) os lugares, pois "o processo social de produção é espacialmente seletivo" (SANTOS, 1997, p. 41). Assim, a produção da cidade estabelece diferentes e desiguais possibilidades de apropriação (e uso) do espaço urbano, reproduzindo

Sociedade \& Natureza, Uberlândia, 20 (1): 205-220, jun. 2008 
uma cidade desigual baseada na contradição existencial do capitalismo por meio dos conflitos de interesse entre suas classes. Nesse processo as classes se organizam no espaço numa lógica de segmentação socioeconômica e nesse sentido são segregadas, e se "separam". Porém essa

separação das classes é simultaneamente ilusória e extremamente real. É ilusória porque as classes figuram-se na mesma sociedade, no mesmo 'todo' que se sistematiza; aliás, há uma única fonte de riqueza social. E é real porque socialmente e na prática há uma separação de classes que como tal é mantida e vai até o conflito (LÉFÈBVRE, 1972, p. 36, grifos do autor).

O espaço é essencialmente contraditório, se constrói no movimento das contradições do processo de reprodução da totalidade social. É um espaço que, para o processo produtivo, une os homens, e é um espaço que, por este mesmo processo, os separa (SANTOS, 1997). O espaço urbano, portanto, é um produto apropriado desigualmente pelas diferentes classes e camadas sociais posto que sua apropriação ocorre em evidente concordância com seu consumo privado. A partir desse definem-se no espaço suas porções desiguais, no qual o espaço é uma mercadoria nutrida de preço e especulação capitalista, objetivando-se inviabilizar ou anular o acesso à determinadas porções do espaço para camadas sociais que detém um poder de aquisição/apropriação menor.

A cidade, em seu tecido urbano, também se apresenta dividida pó meio da produção de uma desigual disposição de fenômenos nas suas distintas parcelas, engendrando uma articulação interna que tende a se configurar de forma diferenciada e segmentada. Dessa forma, estabelecem-se espaços na cidade que dispõem de uma maior concentração de atividades que concedem a esses espaços um maior poder de articulação. Assim, esses espaços exercem atração sobre as demais parcelas do tecido urbano e constituem uma centralidade urbana, que compreende também uma área capaz de gerar e manter fluxos (de pessoas, capitais, mercadorias etc), e não apenas concentrar determinados fixos.
Contudo, a concentração de equipamentos, atividades econômicas e serviços, é extremamente necessária para uma maior dinamização dos fluxos, sobretudo de mercadorias, objetivando que as trocas se realizem de forma mais profícua ao capital. Tal concentração, ao propiciar uma centralização urbana, termina por implicar "numa articulação diferenciada nos usos do solo, alterando a forma urbana e tornandoa segmentada" (SILVA, 2001, p. 108) tanto social e econômica quanto espacialmente.

As questões que envolvem o centro e a centralidade intra-urbana têm sido debatidas por correntes teóricas que apresentam certas distinções entre si. Essas correntes pautam suas análises basicamente em dois conceitos que, embora aparentemente encontrem certa proximidade, trazem divergências importantes: o conceito de estrutura urbana e o de estruturação urbana.

No primeiro grupo de teóricos encontram-se os pesquisadores filiados à Escola Estruturalista de Chicago (também conhecida por Ecologia Urbana) e à Escola Francesa Clássica. Essas escolas, embora com algumas divergências da análise das estruturas urbanas, tendem a considerar:

o centro como algo fixo, preocupando-se com a forma e com a localização, procurando realizar uma minuciosa descrição das áreas em estudo, visando evidenciar o padrão de concentração, estabelecendo modelos que dêem conta de explicar a forma de espaço urbano (SILVA, 2001, p. 108).

Ainda de acordo com Silva (2001), a principal divergência entre essas duas escolas encontra-se nas críticas formuladas pela Escola Francesa Clássica aos estudos de pesquisadores da Ecologia Urbana. As críticas decorriam da constatação de que os estudos da Ecologia Urbana se concentravam demasiadamente na formulação de modelos, em detrimento de estudos sobre a gênese histórica e sobre as características físicas da área em análise.

O segundo grupo de teóricos é identificado por realizar um debate acerca da centralidade intra- 
urbana a partir do conceito de estruturação urbana. Esse conceito não se prende exclusivamente na descrição e interpretação das formas e equipamentos que se encontram fixos, mas compreendem a relevância do debate acerca dos fluxos que se encontram em movimento no território. Assim, essa perspectiva analítica tende a considerar que "a centralidade deve ser entendida a partir dos fluxos que geram de pessoas, de automóveis, de capitais, de decisões, de informações e, sobretudo, de mercadorias" (SILVA, 2001, p. 108).

Nesa direção, depreende-se que o estudo da centralidade urbana se consolida em íntima relação com a própria noção de estrutura e estruturação urbana, e das modificações e rupturas que se processam no tempo. Conceitos que dizem respeito às diferentes disposições (arranjos) no uso e ocupação do solo urbano e as diversas articulações e interações entre estes, resultantes do próprio arranjo. Contudo, esta seria uma centralidade também em movimento, "um movimento dialético que a constrói e a destrói; que a cria ou a estilhaça" (LÉFÈBVRE, 1999, p. 110).

Corroborando com a necessidade de relacionar centralidade e estrutura(ção) urbana, Castells (1983) aponta que a centralidade constituise como elemento fundante das articulações entre os demais elementos que compõem a estrutura urbana, sendo a centralidade permeada por um conteúdo social, ao mesmo tempo em que se apresenta como um local geográfico. Assim, a centralidade expressaria, ao mesmo tempo, um conteúdo e uma forma, posto que se materializa em centros, desdobramentos do centro, sub-centros, dentre outras possibilidades da centralidade se materializar ao assumir formas espaciais na estrutura urbana.

De acordo com Castells (1983, p. 273), o centro representa, por um lado, "a espacialização do processo de divisão técnica e social do trabalho [...]. Por outro lado, podemos defini-lo como especialização geográfica de um certo tipo de unidades de consumo e de serviços". Além disso, é necessário compreender que o centro não se define para sempre como um local fixo na estrutura urbana, o que significa a existência de uma impossibilidade de "assentar o centro urbano, [revelando] que é necessário defini-lo com relação ao conjunto da estrutura urbana" (CASTELLS, 1983, p. 275, grifo do autor).

Acerca da estruturação do espaço urbano, uma questão inicial que merece destaque, segundo observação de Castells (1983), é a de compreender que o espaço urbano é estruturado implica em compreender que este espaço não se (re)organiza ao acaso, mas a partir de determinações e conflitos de interesses. A partir dessa formulação pode-se depreender que a estruturação do espaço faz-se constituída do resultado (sempre inconcluso) dos embates sintetizados principalmente na organização econômica, social, política e os interesses dos grupos sociais dominantes, bem como na própria dialética empreendida e resultante de outro embate, esse entre os fatores internos e externos à cidade.

Neste sentido, apreender o processo de estruturação implica em considerar as dinâmicas e funções das distintas parcelas do tecido urbano e a relevância e relação dessas parcelas individualmente com o processo de reprodução do espaço urbano e na articulação das próprias parcelas. Na medida em que determinados fragmentos do espaço se constituem de maior poder político, econômico, social, e permitem, essencialmente associados aos interesses das elites, induzir o crescimento, os novos investimentos e a valorização da terra urbana, revelam a importância de uma estrutura urbana que atenda prontamente a realização dos interesses desses grupos, atrelando a estrutura à reprodução do espaço, que também deve estar pautada nesses interesses.

Para apreender o processo de estruturação urbana, portanto, é necessário realizar o esforço reflexivo de desvelar a profunda articulação existente entre os conteúdos individuais das distintas parcelas da estrutura com o processo de reprodução do espaço urbano, consubstanciada também com as rupturas e permanências que se expressam ao longo da história no próprio recorte temporal que compreende a estrutura. Desvelar, assim, os conflitos, as

Sociedade \& Natureza, Uberlândia, 20 (1): 205-220, jun. 2008 
contradições que se materializam e se ocultam, impelindo a organização da cidade sempre associada a determinadas racionalidades e interesses em conflito.

Dessa forma, não se encontrando alheia às contradições e conflitos do processo de reprodução social, a estruturação do espaço urbano se expressa permeada pela constante relevância do espaço para o aprofundamento da desigualdade entre as classes sociais. Para tanto ocorre uma manipulação do espaço a partir de determinações na organização e arranjo dos seus conteúdos em parcelas definidas do tecido urbano, realizando um processo que aponta como tendência o aprofundamento das diferenças de classe.

Esse aprofundamento se revela na cidade, no âmbito da estrutura urbana, como resultante da dialética de um campo de força envolto pelos conflitos que se constituem na disputa de acesso e de poder pela terra urbana que por sua vez reafirma os conflitos, sendo reproduzida e apropriada inexoravelmente a partir desses. Por se realizar essencialmente a partir dos interesses dos grupos sociais dominantes, a estrutura urbana se revela intimamente comprometida com esses. A partir dessas observações podemos depreender que "o centro urbano, como a cidade, é produto: por conseguinte, ele exprime as forças sociais em ação e a estrutura de sua dinâmica interna" (CASTELLS, 1983, p. 274, grifo do autor).

Alguns autores, como Sposito (1991, 2004), ao proporem a utilização da expressão estruturação, enfatizam que esta possibilitaria a análise da estrutura como um processo, como uma contínua transformação na qual a estrutura contém e está contida na reprodução dos processos sociais. Nesse sentido, cumpriria observar que a estrutura da cidade não é estática, pois que se encontra em constante movimento a partir do processo de (re)estruturação. Assim, aliase o processo à forma, e a estrutura deve ser entendida como um mero recorte temporal de um processo amplo e contínuo de modificação das próprias estruturas, o processo de estruturação. Nessa direção, a autora observa que: o conceito de morfologia urbana não se referiria [apenas] a uma dada forma urbana (extensão e volume), tal como ela se apresenta configurada espacialmente, mas ao processo de sua gênese e desenvolvimento, segundo os quais podemos explicar essa morfologia e não apenas descrevêla ou representá-la gráfica ou cartograficamente. Aceitando-se essa perspectiva, a morfologia urbana refere-se não apenas à forma, mas também aos conteúdos que orientam essa forma e são por ela redefinidos continuamente (SPOSITO, 2004, p. 66).

Sposito (2004) salienta, ainda, que se deve guardar a expressão reestruturação para os momentos nos quais se contemplam um amplo e profundo conjunto de mudanças na estrutura urbana, partindo da idéia de ruptura com a dinâmica constituinte de uma estrutura anterior, passando o espaço urbano a se (re)produzir pautado nas modificações resultantes. Ou seja, a reestruturação desencadeia-se de uma desestruturação, que marca um rompimento, uma mudança significativa no processo de estruturação. Teríamos, assim, um processo contínuo de estruturação-desestruturação-reestruturação das estruturas urbanas, e esse processo de "estruturação das cidades tem que passar necessariamente pelo entendimento do papel do centro" (SPOSITO, 1991, p. 5), ou dos centros, das diferentes centralidades intra-urbanas.

Assim, é necessário considerar que as rupturas ocorridas no processo de estruturação compreendem uma articulação temporal e dialética entre o velho e a imposição do novo, tanto como conteúdo social quanto como processo espacial, redefinindo ao mesmo tempo o velho e o prosseguimento do processo, constituindo um desequilíbrio que é também um reequilíbrio. De acordo com Santos (1996, p. 227), as rupturas "podem ser consideradas um fator de desagregação, [ou uma] desestruturação, se nos colocamos em relação ao passado, isso é, ao equilíbrio anterior. E de uma reestruturação, se vemos a coisa do ponto de vista que se está dando".

Outro ponto relevante é compreender que a reestruturação que se expressa no espaço intra-urbano 
tem profunda relação com movimentos de reestruturação interurbana, o que Sposito $(2004,2007)$ denomina de reestruturação da cidade e reestruturação urbana, respectivamente. Dessa forma, a autora enfatiza que o movimento de estruturação interna das cidades é incapaz de responder a si mesmo quando desconexo do próprio movimento que implica na atribuição e modificação contínua dos papéis às cidades na rede urbana. Entretanto, isso não significa que esses processos não sejam distintos, embora também sejam complementares.

Uma ruptura significativa com as estruturas urbanas, observada com atenção por diversos estudiosos da geografia urbana como uma característica relevante à intensificação do processo de urbanização decorrente no século XX, consiste num processo de descentralização territorial de equipamentos e atividades para espaços diversos ao que constitui o centro tradicional (principal) das cidades. Esses equipamentos e atividades, para além da descentralização têm-se mostrado capazes de gerar e manter fluxos de forma a desencadear um processo de recentralização conjugado à descentralização territorial.

Neste sentido, diferentes estudos têm apontado como um caminho analítico pertinente que o processo de descentralização conjugado ao de (re)centralização - não mais restrito à dinâmica espacial das metrópoles - seja indissociavelmente debatido a partir da sua relação com o processo de estruturação-desestruturação-reestruturação do espaço urbano. Assim, observa-se que a constituição de uma nova expressão de centralidade em uma cidade outrora centralizada em um único núcleo, redefine nesta a própria noção de centralidade, rompendo e (re)constituindo um novo arranjo e novas formas de articulações e interações entre os diferentes lugares da cidade, que passa a ser poli(multi)nucleada.

Desta forma, realiza-se uma alteração significativa na dinâmica, no arranjo e nas relações entre as distintas parcelas do espaço. Em outras palavras, ocorre "uma tendência de descentralização e de uma conseqüente (re)centralização, expressando uma centralidade multicêntrica, que amplia a espacialização intra-urbana, distribuindo os fluxos e ampliando a diferenciação/segmentação urbana" (SILVA, 2001, p. 111). A centralidade torna-se multicêntrica posto que mesmo com "a emergência de outros 'centros', o principal e cada um deles desempenha um papel de concentricidade" (SPOSITO, 1991, p. 6-7).

Nesta direção, depreende-se que não há uma mera mudança na localização das atividades que se encontravam no centro principal ou uma dispersão dessas atividades por outras áreas da cidade, mas uma lógica locacional profícua à dinâmica econômica de determinadas atividades que expressam uma "concentração descentralizada" frente ao centro principal, expressando uma redefinição da centralidade intra-urbana, que se torna múltipla e plural, resultante "do que muda com relação ao que permanece, no plano territorial e no plano das representações que se constróem sobre o espaço urbano e suas áreas centrais" (SPOSITO, 2001, p. 238).

De acordo com Sposito (1998), a relevância da análise da redefinição da centralidade intra-urbana pode ser sintetizada a partir de quatro dinâmicas que expressam um conjunto de mudanças sociais, econômicas e espaciais em curso. Estas mudanças se realizam impelindo uma contínua recomposição da estruturação intra-urbana conjugando rupturas e continuidades expressas através: (1) dos novos padrões de localização dos equipamentos comerciais e de serviços e seus impactos frente ao papel do centro principal; (2) das transformações econômicas expressas em formas flexíveis de produção que impõem fortes vínculos interurbanos na estruturação intra-urbana; (3) das novas dimensões da redefinição da centralidade intra-urbana, que embora não seja um processo novo, passa a ocorrer também nas cidades médias; (4) da redefinição do cotidiano frente ao crescimento da importância conferida ao lazer e ao tempo destinado ao consumo.

Nessa perspectiva, a autora procura reforçar a necessidade de utilização do conceito de

Sociedade \& Natureza, Uberlândia, 20 (1): 205-220, jun. 2008 
(re)estruturação urbana em detrimento do conceito de estrutura urbana. Isso devido à capacidade analítica e de fundamentação crítica que o conceito de estruturação proporciona ao possibilitar respostas para questões cruciais que não se encontram restritas aos usos do solo e ao que está fixo no território, mas sobretudo aos fluxos gerados e mantidos pelo arranjo e rearranjo do que está localizado no território, bem como aos processos sociais gerados pelo (re)arranjo e aos quais esse mesmo (re)arranjo responde. Assim, Sposito (2001) afirma que embora o centro se revele por determinados atributos localizados ou fixados no território, a centralidade se desvela pelo que se movimenta no território. Ou seja, "a centralidade pode ou não ser fugaz, efêmera ou transitória, porque ela não se institui apenas pelo que está fixo no espaço, mas pelas mudanças ocorridas no decorrer do tempo, no uso, apropriação e sentido dados aos espaços e deles apreendidos" (SPOSITO, 2001, p. 239).

Portanto, não apenas a descentralização de determinadas atividades correspondem à criação de novas expressões de centralidade. Essas se criam essencialmente em decorrência dos fluxos que as atividades geram e dos quais decorrem sua própria descentralização, que ao se estabelecerem e se intensificarem geram novas centralidades. Ou seja, conforme aponta Sposito (2001, p. 236), ocorre uma articulação de duas dinâmicas econômico-territoriais: "a descentralização territorial dos estabelecimentos comerciais e de serviços e a de recentralização dessas atividades".

A expressão completa desse processo é a diversificação das expressões da centralidade intra-urbana e, ainda, da centralidade interurbana, visto que novas formas de comércio promovem novos fluxos entre cidades de diferentes portes, permitindo a emergência de uma centralidade múltipla e complexa, no lugar da centralidade principal e muitas vezes única, que marcava a estruturação interna das cidades até há algumas décadas (SPOSITO, 2001, p. 236, grifo da autora).

A crescente presença dessa dinâmica, expressa na descentralização de atividades comerciais e de serviços caracterizada pela recentralização exercida por essas novas áreas no território das cidades, aponta para um processo de aumento e diversificação de áreas centrais. Tal alteração têm sido verificada também nas cidades médias, o que denota uma alteração nas formas contemporâneas de reprodução do capital adentrando a dinâmica espacial de outras categorias de cidades que não as metrópoles. Sposito (2001) observa que a freqüente incidência desse processo, modificando a concepção de centro e centralidade frente à estruturação intra-urbana, permite constatar a ocorrência de uma centralidade múltipla, exercida por diferentes e diversas áreas centrais.

Uma outra ocorrência de centralidade é derivada da própria multiplicidade temporal da expressão da centralidade dessas diferentes áreas centrais. Sendo o centro caracterizado, conforme já observado, pelo que se encontra fixo no território, mas a centralidade pelo que no território se movimenta, a centralidade se presta a modificações que ocorrem em variações temporais mais curtas e inconstantes. Dessa forma, constata-se que a centralidade pode ser redefinida continuamente em curtos intervalos de tempo, o que torna possível que a sua apreensão se realize a partir da noção de centralidade cambiante. Essa apreensão, de acordo com Sposito (2001), é resultante não apenas das relações decorrentes da articulação entre o que está fixo e o que está em movimento, mas das variações impressas e expressas nessa articulação no decorrer de determinados intervalos de tempo. Esses intervalos podem, inclusive, ser de curto período, estabelecendo diferenças de fluxos nas diversas áreas centrais, em diferentes horários de um mesmo dia ou entre diferentes dias da semana. Ou seja, a centralidade exercida por determinada área pode acentuar-se ou dissipar-se momentaneamente e em diferentes intensidades.

Para além da centralidade múltipla, e paralelamente a esta, as cidades também passam a responder à necessidade de uma centralidade polinucleada, que caracteriza uma centralidade diferenciada. Isso ocorre porque, como constatou 
Sposito (1991, 2001), as novas áreas centrais geram e mantém um determinado padrão de consumo que implica uma "funcionalidade" e acessibilidade (não apenas tangível, ou seja, não apenas pelas facilidades propiciadas pelas suas vias de acesso) para determinados grupos e camadas sociais de elevado poder aquisitivo, que se sentem estimulados ao atendimento e realização dos padrões de consumo das novas centralidades. Dessa forma, as novas centralidades terminam por expressar centralidades socialmente segmentadas no interior das cidades.

Uma outra forma de manifestação das novas centralidades é resultante do reforço da centralidade urbana por meio da articulação de duas escalas espaciais, o que implica, de acordo com Sposito (2001), numa centralidade complexa. Essa decorre da articulação entre a multiplicação da centralidade na escala intra-urbana com o reforço da centralidade exercida pelas cidades nas quais se apresenta a ocorrência de novas centralidades. Nesse sentido, a centralidade torna-se complexa, gerando ao mesmo tempo um reforço e uma modificação na articulação dos fluxos entre a escala intra-urbana e interurbana, pois as novas centralidades compreendem uma lógica a partir da "escolha de localizações que possam ser estratégicas de sorte a atrair mercados consumidores de mais de uma cidade" (SPOSITO, 1998, p. 34). Por isso, reforçam a centralidade da cidade ao mesmo tempo em que multiplicam a centralidade na cidade.

\section{Redefinição da centralidade em cidades médias}

Acerca dos principais processos contemporâneos, neste contexto de natureza espaçotemporal, que redefinem os papéis das cidades médias, Sposito (2006) aponta para serem os mais significativos os processos que se enquadram em duas vertentes: concentração e centralização econômica e a melhoria e diversificação dos sistemas de transportes e telecomunicações.

Para a autora, essa primeira vertente de processos caracterizada pela concentração e centralização econômica constitui-se pela emergência de novos meios técnicos e informacionais que vêm possibilitando novas estratégias e lógicas de atuação das empresas de diferentes portes. Nessa direção:

a análise desses processos interessa na medida em que tanto a concentração como a centralização econômicas requerem e propiciam (des)concentração espacial e/ou centralização espacial dos capitais, o que implica novas estratégias por parte de empresas, grupos econômicos ou conglomerados (SPOSITO, 2006, p. 8).

Isso se verifica, a título de exemplo, com a desconcentração espacial de variados ramos de atividades produtivas das metrópoles para cidades de médio porte. Esse processo, se por um lado altera ou amplia os papéis urbanos das cidades médias, caracterizando a desconcentração espacial, por outro lado amplia também os papéis da metrópole, pois gera uma (re)centralização dos capitais no que tange à localização dos centros de comando, o que implica essencialmente na centralização do capital financeiro (SPOSITO, 2006). Disso depreende-se que no momento atual "a lógica do capital industrial é redefinida, produz-se um deslocamento, no espaço, dos estabelecimentos industriais sem que essa desconcentração traga, consigo, a descentralização do capital" (CARLOS, 2005, p. 30).

No caso brasileiro, de acordo com Botelho (2002), na década de 1970 a região metropolitana de São Paulo chegou a participar com $44 \%$ da produção industrial do país. Contudo, entre a década de 1970 e 1990, a participação do interior paulista na produção industrial estadual subiu de $25 \%$ para $47 \%$.

Ao analisar as indústrias automobilísticas, o autor confirma que a desconcentração também se expressa na localização das novas indústrias e dos novos investimentos do setor em cidades de porte médio, havendo uma desconcentração também para outros estados e regiões da federação. Exemplos desse processo são os casos da General Motors em GravataíRS, da Audi/Volkswagen e Renault em São José dos Pinhais-PR, da Mitsubichi em Catalão-GO, da Ford em Camaçari-BA, dentre outros exemplos que

Sociedade \& Natureza, Uberlândia, 20 (1): 205-220, jun. 2008 
expressam uma mudança ou diversificação na escolha de localização dos investimentos do setor industrial no país a partir da década de 1980 .

A outra vertente analisada por Sposito (2006) compreende as modificações que se acentuaram a partir da década de 1980 quanto à considerável melhoria e a própria diversificação dos sistemas de transportes e comunicações que trouxeram implicações no que tange a diminuição de custos com circulação, tanto de mercadorias e informações como de pessoas.

A essas alterações acrescentem-se as possibilidades abertas pela existência de novos tipos de mídia que favorecem a difusão de imagens e de valores que ampliam o consumo e estimulam a expansão territorial de capitais, empresas, grupos e conglomerados, da escala regional, passando pela nacional e chegando à internacional (SPOSITO, 2006, p. 10).

Deste processo, a autora aponta para a tendência que se instaura com a diminuição dos custos com circulação de mercadorias na constituição dos preços finais, propiciando uma maior mobilidade territorial de equipamentos direcionados ao consumo, e não apenas de setores produtivos. Contudo, como há necessidade de uma determinada densidade de consumidores para que certa localidade seja interessante para investimentos dos capitais que se desconcentram, as cidades médias apresentam-se como espaços privilegiados de alocação destes investimentos, dos quais decorre o fortalecimento do papel destas cidades no que tange ao oferecimento de funções, bens e serviços aos moradores da sua hinterlândia e de áreas rurais ou urbanas mais ou menos distantes. Assim, este processo implica no reforço ao papel das cidades médias como espaços de consumo locais e regionais, reforçando a centralidade e intermediação destas cidades.

Um outro aspecto abordado pela autora diz respeito às modificações do período atual na modernização do setor agropecuário, ocorrendo uma dupla relação espaço-temporal. Isto porque, ao mesmo tempo em que o setor exige relações espaciais marcadas pela contigüidade e sob domínio de uma cidade média, por outro lado exige também relações de sobreposição e articulação com outras escalas espaciais não definidas pela contigüidade, resultantes sobretudo das modernas formas de comunicação.

Contudo, por último, Sposito (2006) propõe uma compreensão das cidades médias que relacione essencialmente duas vertentes analíticas supra citadas - os processos decorrentes da concentração e centralização econômica conjugados com a melhoria e diversificação dos sistemas de transportes e telecomunicações. Isto implica em considerar as (novas) formas contemporâneas com que as atividades econômicas dos diversos ramos comerciais e de serviços vêm se organizando espacialmente "como parte de um processo de concentração econômica que se acompanha de desconcentração espacial" (SPOSITO, 2006, p. 12), bem como as formas de competitividade que se desenvolvem entre as cidades de porte médio para se apresentarem mais rentáveis e propícias para receberem os investimentos que se desconcentram espacialmente.

Desta forma, com a insurgência destes investimentos, modifica-se a dinâmica de produção e estruturação do espaço intra-urbano das cidades médias, bem como também a forma como estas cidades se relacionam e interagem com a sua hinterlândia, com outras cidades médias e com as metrópoles.

Os novos processos sociais e espaciais que transformam os papéis das cidades médias, redefinindo-os, podem ser analisados a partir das mudanças ocorridas na dinâmica intra-urbana, tendo como ponto de partida o movimento econômico que subsume as cidades médias pelas prementes necessidades da reprodução e acumulação do capital no atual momento histórico.

Esse movimento econômico delineia um problema, na medida em que impele nas cidades médias a criação de novas centralidades e artefatos mais profícuos à imposição de tempos hegemônicos, 
ou seja, mais profícuos ao novo contexto da dinâmica econômica. Esse contexto, ao redefinir os papéis das cidades médias, revela na dinâmica intra-urbana destas cidades as mudanças resultantes do embate entre o que existe e o que se impõe, embate que vela e desvela as contradições do movimento do mundo nos lugares.

Para o desenvolvimento analítico da redefinição da centralidade nas cidades médias, partese da hipótese de que, nas cidades médias, as novas áreas centrais são criadas para estas cidades se adaptarem e "atenderem" às mudanças decorrentes da dinâmica econômica a partir da mundialização do capital. Tal fato denota, nestas cidades, um processo de redefinição dos seus papéis, bem como revela, na maioria dos casos, a não funcionalidade e/ou incapacidade dos centros tradicionais em receber e "atender" às necessidades contemporâneas da reprodução e acumulação do capital. Ou seja, são os novos papéis determinados às cidades médias no processo de mundialização do capital que impelem nestas cidades a necessidade de criar novas áreas centrais, tornando as cidades médias atrativas à localização de novos artefatos ou equipamentos comerciais e de serviços pautados em novos fluxos, materiais e imateriais, de capital e mercadorias que reproduzem novos signos, idéias, valores, contradições, discursos, dentre outros.

As cidades médias apresentam-se então como espaços privilegiados para o atendimento dessas necessidades de reprodução do capital no momento em que ocorre um processo de descentralização espacial do capital produtivo ou do terciário. Isso porque essas cidades, além de situarem-se em localizações relevantes, possuem requisitos importantes quanto às redes de transporte e comunicação e exercem uma centralidade em nível interurbano sobre determinada contigüidade territorial, atraindo, portanto, consumidores, o que faz com que estes novos investimentos sejam rentáveis economicamente. Estes investimentos, ao se instalarem, reforçam a própria centralidade que estas cidades já exerciam, fato que inclusive otimiza a reprodução dos novos valores decorrentes da imposição do tempo hegemônico em outros espaços territorialmente descentralizados na rede urbana.

\section{Considerações para o prosseguimento do debate}

Por se consolidarem essencialmente substanciadas pelas atividades comerciais e de serviços, as novas centralidades constituem-se de equipamentos que geram e mantém padrões e necessidades de consumo que respondem ao conteúdo do novo contexto da reprodução do capital, estruturada por meio de fluxos de natureza material e imaterial. Essas necessidades de consumo, por subjugarem ainda mais o tempo livre à ampliação do mundo da mercadoria e as mediações das relações sociais ao valor de troca, expressam também o crescente distanciamento entre o indivíduo e a produção humano-genérica consciente, resultando no aprofundamento do estranhamento da vida cotidiana na cidade.

Neste sentido, ao reforçar e consolidar uma ruptura tênue que não se define claramente entre o tempo de trabalho e o tempo livre, subjugam outros momentos cotidianos à reprodução e acumulação do capital, ou seja, à produção e realização do valor. Isso se consolida ao mesmo tempo em que se intensifica e precariza o trabalho num processo produtivo com profundas alterações de âmbito qualitativo. Tais fatos impulsionam um processo de esvaziamento de sentido do homem como ser social — tendendo a não realizarse senão no sentido da realização da mercadoria tanto dentro quanto fora do trabalho, principalmente pelos novos fluxos imateriais. Estes fluxos, ao se estabelecerem e se intensificarem no sistema de mediação social, terminam por não permitir observar separadamente os momentos cotidianos, assim como dificultam a própria apreensão da intensidade das suas expropriações para o homem e reapropriações pelo capital.

Portanto, as novas centralidades apresentamse como movimentos da dinâmica espacial relevantes ao debate acerca da ofensiva do capital sobre os momentos de "não-trabalho", que, cada vez mais, apresentam-se como funcionais ao capital no processo

Sociedade \& Natureza, Uberlândia, 20 (1): 205-220, jun. 2008 
da sua expropriação devido à premência do tempo livre à reprodução do sistema produtivo como tempo de consumo ou de lazer subvertido. Ou seja, as novas centralidades revelam as presentes imposições do tempo hegemônico ao tempo livre como condição de reprodução do capital.

A criação de novas centralidades evidencia também a questão do planejamento e da gestão urbana e o peso dos agentes envolvidos. Isso devido ao fato que a análise das novas centralidades implica em compreender as formas de articulação e o papel exercido pela ação dos agentes do poder público local e de setores da iniciativa privada em impelir e direcionar o processo de reestruturação do espaço urbano da cidade, revelando os interesses destes agentes.

Isso ocorre porque o processo de reestruturação caracterizado principalmente pela centralidade múltipla e polinucleada - poli(multi)nucleada - , na qual as centralidades são incorporadas de formas desiguais no que tange à sua acessibilidade, são, portanto, espaços de "uso" (e de conflito entre propriedade e uso, apropriação), apropriação e realização de padrões de consumo de segmentos sociais urbanos distintos e em certa medida com uma maior homogeneidade interna, o que pressupõe que as novas centralidades atendem a interesses de determinados grupos sociais em detrimento de outros.

\section{REFERÊNCIAS}

BELLET SANFÉLIU, C.; LLOP TORNÉ, J. M. Ciudades intermedias: entre territorios concretos y espacios globales. Ciudades y territorio - estudios territoriales, Madrid, v. XXXVI, n. 141-142, 2004a.

Miradas a otros espacios urbanos: las ciudades intermedias. Scripta Nova, Barcelona, v. 8 , n. 165,2004 b.

BOTELHO, Adriano. Reestruturação produtiva e produção do espaço: o caso da indústria automobilística instalada no Brasil. Revista do Departamento de Geografia, São Paulo, n. 15, 2002.
CASTELLO BRANCO, Maria Luisa. Cidades médias no Brasil. In: SPOSITO, E. S.; SPOSITO, M. E. B.; SOBARZO, O. (Org.). Cidades médias: produção do espaço urbano e regional. São Paulo: Expressão Popular, 2006.

CASTELLS, Manuel. A questão urbana. São Paulo: Paz e terra, 1983.

CARLOS, Ana Fani A. A (re)produção do espaço urbano. São Paulo: EDUSP, 1994.

O espaço urbano: novos escritos sobre a cidade. São Paulo: Contexto, 2004.

. A reprodução da cidade como "negócio". In: CARLOS, Ana Fani A.; CARRERAS, Carles. Urbanização e mundialização: estudos sobre a metrópole. São Paulo: Contexto, 2005.

COSTA, Eduarda Marques da. Cidades médias: contributos para sua definição. Finisterra, Lisboa, v.XXXVII, n. 74, 2002.

LÉFÈBVRE, Henri. O pensamento marxista e a cidade. Lisboa: Ulisseia, 1972.

A revolução urbana. Belo Horizonte: UFMG, 1999.

LLOP TORNÉ, J. M.; BELLET SANFÉLIU, C. Ciudades intermedias y urbanización mundial. Unesco - UIA - Ministerio de Asuntos Exteriores. Lleida: Ed. Ajuntament de Lleida, 1999.

MOTTA, Diana M. da; AJARA, Cesar. Configuração da rede urbana do Brasil. Revista Paranaense de Desenvolvimento, Curitiba, n. 100, jan/jun, 2001.

SALGUEIRO, Teresa Barata. Lisboa, metrópole policêntrica e fragmentada. Finisterra, Lisboa, v.XXXII, n.63, 1997.

SANTOS, M. Por uma geografia nova: da crítica da geografia a uma geografia crítica. São Paulo: Hucitec, 1978. 

1996.

A natureza do espaço. São Paulo: Hucitec,

Pensando o espaço do homem. 4. ed. São

Paulo: Hucitec, 1997.

SERPA, Ângelo. A ampliação do consumo e os conflitos entre o público e o privado na cidade contemporânea: questões para debate. In: CARLOS, A. F. A.; LEMOS, A. I. G. (Org.). Dilemas urbanos: novas abordagens sobre a cidade. 2. ed. São Paulo: Contexto, 2005.

SILVA, William Ribeiro da. Centro e centralidade: uma discussão conceitual. Formação, Presidente Prudente, n. 8, 2001.

SOARES, Beatriz Ribeiro. Repensando as cidades médias brasileiras no contexto da globalização. Formação, Presidente Prudente, n. 6, 1999.

SOARES, Paulo Roberto R. Reestructuración urbana y producción de la ciudad: el Brasil urbano a principios del siglo XXI. In: CAPEL, Horacio. Ciudades, arquitectura y espacio urbano. Almería: Ed. Caja Rural de Almería, 2003.

SPOSITO, Maria Encarnação Beltrão. O centro e as formas de expressão da centralidade urbana. Geografia, São Paulo, n. 10, 1991.

- A gestão do território e as diferentes escalas da centralidade urbana. Território, Rio de Janeiro, Ano III, n. 4, jan/jun, 1998.

. A urbanização da sociedade: reflexões para um debate sobre as novas formas espaciais. In: DAMIANI, A. L.; CARLOS, A. F. A.; SEABRA, O. C. de L. (Org.). O espaço no fim de século: a nova raridade. São Paulo: Contexto, 1999.

Novas formas comerciais e redefinição da centralidade intra-urbana. In: SPOSITO, Maria Encarnação Beltrão (Org.). Textos e contextos para a leitura geográfica de uma cidade média.
Presidente Prudente: Pós-graduação em Geografia da FCT/UNESP, 2001.

O chão em pedaços: urbanização, economia e cidades no estado de São Paulo. Presidente Prudente: [s.n.], 2004.

O estudo das cidades médias brasileiras: uma proposta metodológica. In: Anais do $5^{\circ}$ Seminário Internacional de Estudos Urbanos. Belo Horizonte: PUC-Minas, 2006.

Reestruturação urbana e segregação socioespacial no interior paulista. In: Anais do $9^{\circ}$ Colóquio Internacional de Geocrítica. Porto Alegre: UFRGS, 2007.

TOURINHO, Andréa de Oliveira. Centro e centralidade: uma questão recente. In: CARLOS, A. F. A.; OLIVEIRA, A. U. de (Org.). Geografias das metrópoles. São Paulo: Contexto, 2006.

UNITED NATIONS. World urbanization prospects: the 2005 revision. New York: United Nations Publication, 2006.

WHITACKER, Arthur Magon. Inovações tecnológicas, mudanças nos padrões locacionais e na configuração da centralidade em cidades médias. In: Anais do $9^{\circ}$ Colóquio Internacional de Geocrítica. Porto Alegre: UFRGS, 2007.

Sociedade \& Natureza, Uberlândia, 20 (1): 205-220, jun. 2008 